\title{
Follow-up patency of side branches covered by intracoronary Palmaz-Schatz stent
}

\begin{abstract}
To assess the risk of late side branch occlusion after Palmaz-Schatz stent deployment, we analyzed the angiographic evolution of 62 patients treated by successful stent implantation who had a total of $\mathbf{8 5}$ side branches starting from the stented segment. Side branches were considered minor $(n=39)$ when the diameter was $<1 \mathrm{~mm}$ and intermediate $(n=46)$ when the vessel had $\geq 1 \mathrm{~mm}$ diameter. One angiographic follow-up study was available in all patients at $8 \pm 5$ months. Eight minor branches presented some degree of stenosis at origin before stent deployment (4 totally occluded). After stent deployment, $32(82 \%)$ of 39 remained unchanged and 3 became occluded. Late progression at origin occurred in 4 of 34 ( 3 occluded). Before stent deployment, $\mathbf{4 8 \%}$ of the intermediate branches had some compromise degree at their starting point ( 1 totally occluded). Eight of 45 intermediate branches became occluded after stent implantation. Late progression at origin happened in 5 of 32 branches (2 occluded). Some degree of follow-up stenosis regression at the origin was observed in $22(26 \%)$ of 85 arteries. Neither clinical nor angiographic factors could be identified as predictors of late side branch occlusion or stenosis progression at its origin. Later occlusion or progression at origin of a side branch covered by a Palmaz-Schatz stent seems to be an uncommon occurrence $(7 \%$ and $12 \%$ respectively) that cannot be predicted by angiographic or clinical factors. On the contrary, regression at follow-up of a side branch-origin stenosis can also come about. (AM HEART $J$ 1995; 129:436-40.)

Manuel Pan, MD, Alfonso Medina, MD, José Suárez de Lezo, MD, Miguel Romero, MD, Francisco Melián, MD, Djordje Pavlovic, MD, Enrique Hernández, MD, José Segura, MD, José Marrero, MD, Francisco Torres, MD, Diego Giménez, MD, and José R. Ortega, MD Cordoba and

Las Palmas de Gran Canaria, Spain
\end{abstract}

Stenting of coronary lesions sometimes involves the coverage of small or intermediate side branches located in the vicinity of the target lesion. There is little information regarding the evolution of such potentially compromised vessels. ${ }^{1,2}$ Our study focused on the angiographic follow-up of patients treated by successful Palmaz-Schatz stent implantation who had one or more side branches starting from the stented segment. The purposes of the study were to learn the incidence of late side-branch compromise and to analyze factors influencing such events.

\section{METHODS}

Patients. Between May 1991 and September 1993, 207 Palmaz-Schatz stents were successfully implanted in 185

From the Hospital "Reina Sofía," University of Córdoba; and the Hospital del Pino, University of Las Palmas, Las Palmas de Gran Canaria.

Received for publication Jan. 27, 1994; accepted May 1, 1994.

Reprint requests: Manuel Pan, MD, Servicio de Cardiología, Hospital Reina Sofia, Avda, Menéndez Pidal 1, 14004-Córdoba, Spain.

Copyright $\odot 1995$ by Mosby-Year Book, Inc.

$0002-8703 / 95 / \$ 3.00+0 \quad \mathbf{4} / \mathbf{1} / \mathbf{6 0 7 6 3}$ patients. Sixty-three of those patients were excluded from analysis: 10 had a definitive subacute occlusion, 4 had elective surgery before discharge, and 49 were still waiting for angiographic reevaluation or had been rejected for restudy. In the remaining 122 patients an angiographic follow-up was available $7 \pm 5$ months later. Sixty-three of those patients had at least one side branch covered by the stent. This group was the object of our study. The mean age was $55 \pm 8$ years. Indications for stenting were (1) abrupt closure after percutaneous transluminal coronary angioplasty (PTCA), 9 (14\%); (2) suboptimal PTCA results (dissection or recoil), 18 (29\%); (3) chronic total occlusion, 23 (37\%); (4) obstinate restenosis after balloon angioplasty or directional coronary atherectomy, $8(13 \%)$; and (5) unfavorable lesions for PTCA, 4 (7\%). The clinical and angiographic baseline data of the study group are shown in Table I.

Technique. The technique used for stent deployment has been previously described in detail. ${ }^{3,4}$ All patients were receiving medical treatment with aspirin and antianginal drugs. Written, informed consent was obtained from all patients before the procedure. During the procedure, a bolus of intravenous heparin was administered $(15,000 \mathrm{IU})$, and a continuous infusion was maintained until oral anticoagulation was effective. No sheathed delivery system was 
used. The stents were always delivered crimped onto a low-profile balloon catheter. The stent was expanded to reach a size slightly higher than the vessel diameter $(3.2 \pm 0.3 \mathrm{~mm})$.

Immediate and follow-up angiographic studies. Eighty-five jeopardized side branches originating from the stented segment were identified. Side branches were considered minor $(n=39)$ when the diameter was $<1 \mathrm{~mm}$ and intermediate $(n=46)$ when the vessel had $\geq 1 \mathrm{~mm}$ diameter (range 1 to $2 \mathrm{~mm}$ ). The location and size were as follows: 26 septal perforator (13 minor and 13 intermediate), 21 diagonal (4 minor and 17 intermediate), 29 right ventricular (17 minor and 12 intermediate), 8 obtuse marginal (5 minor and 3 intermediate), and 1 intermediate circumflex branch.

Late progression of stenosis at origin was defined as a $>20 \%$ worsening of the diameter in a previously diseased side branch or the development of a total occlusion independent of the previous situation. In side branches without stenosis after stent implantation, late progression was considered when $>50 \%$ stenosis came about. Regression of the stenosis at origin was considered when a $>50 \%$ reduction in percentage of stenosis occurred. In case of an occluded side branch after stenting, regression was also considered if the side branch was patent at follow-up. All patients underwent at least 1 angiographic follow-up study $8 \pm 5$ months later. The serial analyses were performed in the same selected projection (in which the target lesion and side branch narrowing were better observed). Restenosis of the parent vessel was defined as a $>50 \%$ stenosis at followup. Quantitative angiographic studies were performed to obtain vessel diameter, percentage of stenosis, and minimal lumen diameter. Small side branches were drawn and measured manually with calipers.

Statistics. Data are expressed as mean \pm SD. A Student-Fisher unpaired $t$ test was used to compare quantitative data from patients with or without late progression. Either the chi-squared or Fisher exact test was used to compare qualitative variables. A $p<0.05$ value was considered statistically significant.

\section{RESULTS}

Immediate results. The percentage of stenosis of the parent vessel changed from $87 \% \pm 11 \%$ to $5 \% \pm 12 \%$ and the minimal lumen diameter from $0.4 \pm 0.3 \mathrm{~mm}$ to $3 \pm 0.4 \mathrm{~mm}$. Fig. 1 shows the acute changes in the patency of the 85 side branches covered by the stent.

Minor side branches. Eight presented some degree of stenosis at origin (4 totally occluded); 1 was already induced by balloon dilation before stent implantation. After deployment, 32 (82\%) of 39 remained unchanged, and 3 became occluded (Fig. 1, $A$ ). Neither clinical event nor enzymatic elevation was observed after side branch occlusion.

Intermediate side branches. Fig. 1, $B$ shows the angiographic evolution of intermediate side branches. Before stenting, $22(48 \%)$ of 46 patients had some
Table I. Baseline characteristics of patients $(\mathrm{n}=62)$

\begin{tabular}{lc}
\hline Age (yx) & $55 \pm 8$ (range 34-72) \\
Sex & $54(87 \%)$ \\
Men & $8(13 \%)$ \\
Women & \\
Type of lesion & $51(83 \%)$ \\
De novo & $11(17 \%)$ \\
Restenosis & \\
Clinical condition & $8(13 \%)$ \\
Stable angina & $33(53 \%)$ \\
Unstable angina & $21(34 \%)$ \\
Post-fibrinolysis & \\
Treated artery & $33(53 \%)$ \\
LAD & $22(36 \%)$ \\
RCA & $7(\mathbf{1 1 \%})$ \\
Cx & $3.1 \pm 0.3$ \\
Vessel diameter (mm) & $9 \pm 4$ \\
Lesion length (mm) & $87 \pm 11$ \\
Stenosis (\%) & $0.4 \pm 0.3$ \\
Minimal lumen diameter (mm)
\end{tabular}

$L A D$, Left anterior descending artery; $R C A$, right coronary artery; $C x$, circumflex artery.

degree of compromise at branch origin, with 1 being induced after previous balloon dilation. After deployment, 8 (17\%) of 45 became occluded. Three of the 8 patients had prolonged chest discomfort with slight creatine phosphokinase elevation, although no patient showed significant electrocardiographic changes.

Late results. After $8 \pm 5$ months, the percentage of stenosis and minimal lumen diameter at parent vessel level were $36 \% \pm 24 \%$ and $1.9 \pm 0.7 \mathrm{~mm}$, respectively; $20(32 \%)$ of 62 patients fulfilled the restenosis criterion.

Minor side branches. Late progression at origin occurred in 4 (12\%) of 34 minor side branches. Three became occluded without significant clinical event.

Intermediate side branches. Five showed late progression according to the previous definition. Two late occlusions took place, one (diagonal branch) associated with non-Q-wave myocardial infarction 1.5 months after the procedure. At follow-up, 41 intermediate side branches remained unchanged (Fig. 2) or with some degree of improvement at stenosis origin.

Neither clinical nor angiographic factors could be identified as predictors of late side branch occlusion or stenosis progression at origin (Table II). In addition, some degree of stenosis regression at origin was observed in 22 of the 85 analyzed side branches (Fig. 1).

\section{DISCUSSION}

The Palmaz-Schatz stent has been proved to be of worth in improving suboptimal results after PTCA 


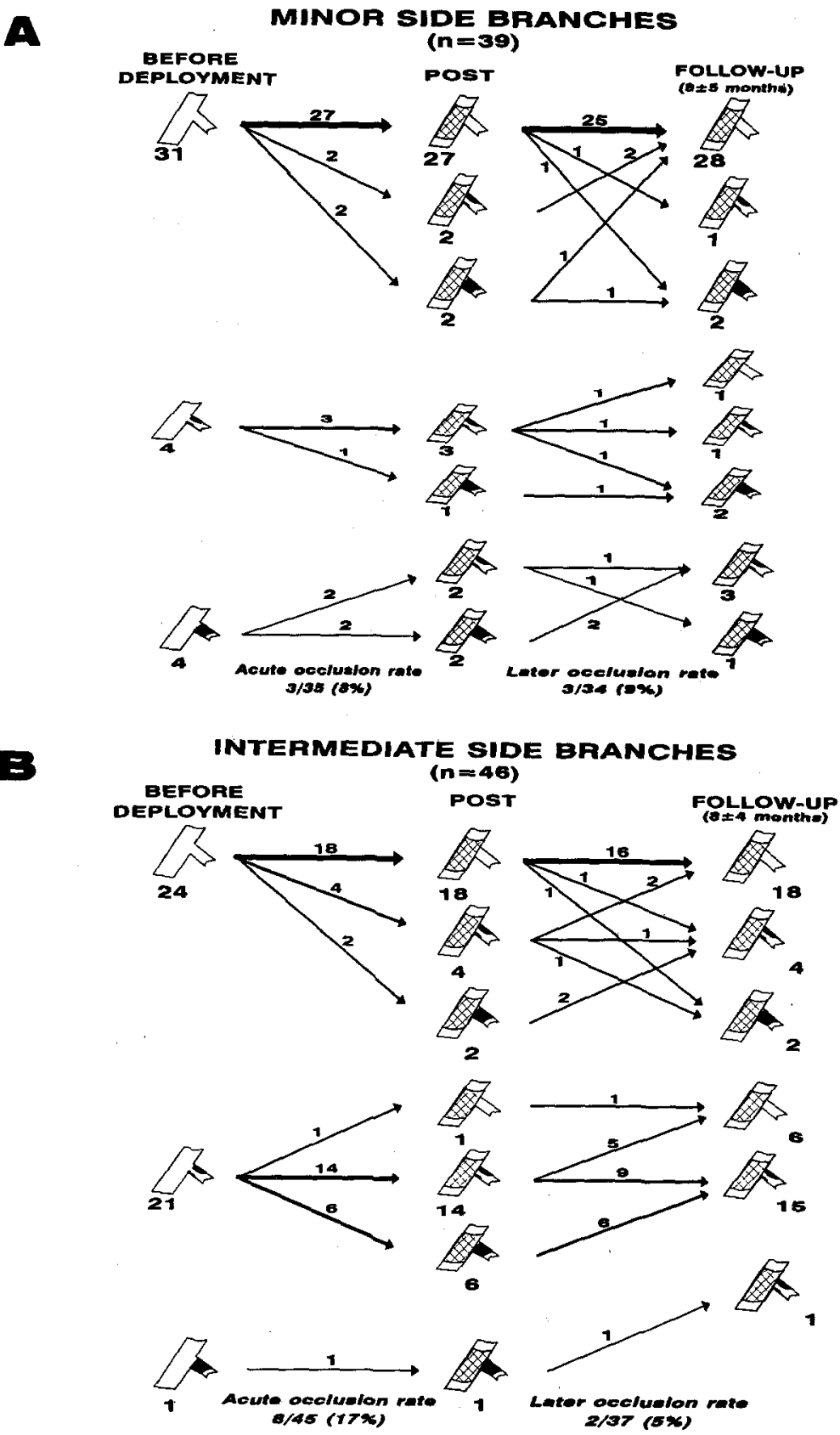

Fig. 1. Angiographic changes of minor (A) and intermediate (B) side branches after being use of PalmazSchatz stent. Top left, No compromise; middle left, stenosis $>50 \%$; bottom left, total occlusion.

and in reducing the restenosis rate.$^{5-9}$ However, owing to its particular design (small distance of metal structure), the coverage of major side branches supplying significant myocardium must be carefully estimated because of possible later compromise and the inability to cross or dilate an ulterior lesion located in this side branch. Our policy has been to avoid such an important vessel; therefore in 30 of 185 patients at least one divided Palmaz-Schatz stent was implanted to preserve potentially compromised side branches. ${ }^{10}$ Sometimes, however, we were forced to cover side branches in the vicinity of the target lesion (Fig. 2). Our study analyzed the angiographic evolution of such minor or intermediate vessels $(\leq 2 \mathrm{~mm})$.

After stent deployment, acute changes came about with significant progression of the disease at the side branch origin ( $14 \%$ of side branch occlusion). This occlusion rate is slightly higher than that observed in 


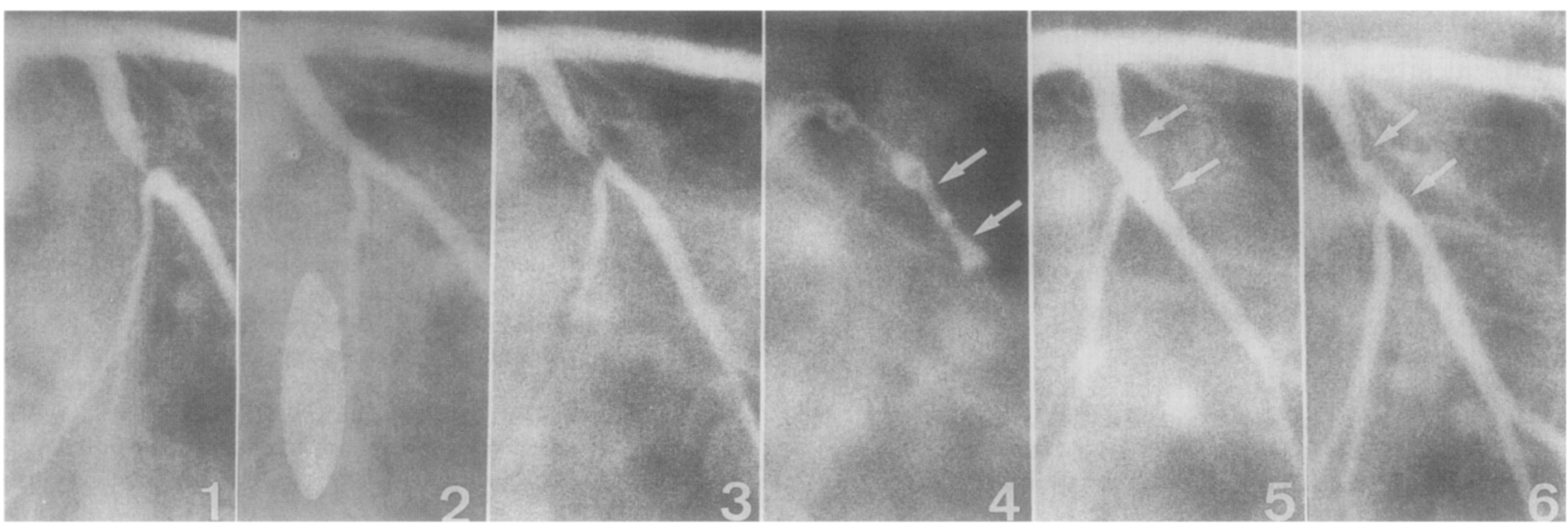

Fig. 2. Serial angiographic study of patient with Palmaz-Schatz stent implanted at obtuse marginal coronary artery. There is no compromise of covered side branch (circumflex branch) in spite of restenosis at origin of stented segment. 1, Baseline; 2,1 min after balloon angioplasty; 3,10 min after balloon angioplasty; 4, stent deployment; 5 , immediately after stent implantation; 6,5 months after implantation. Arrows indicate position of stent.

Table II. Factors determining late progression of stenosis at origin

\begin{tabular}{|c|c|c|c|c|c|c|}
\hline & \multicolumn{3}{|c|}{ Minor side branches } & \multicolumn{3}{|c|}{ Intermediate side branches } \\
\hline & $\begin{array}{l}\text { Worsening } \\
\quad(n=4)\end{array}$ & $\begin{array}{l}\text { No progression } \\
\quad(n=30)\end{array}$ & p Value & $\begin{array}{l}\text { Worsening } \\
\quad(n=5)\end{array}$ & $\begin{array}{l}\text { No progression } \\
\quad(n=32)\end{array}$ & $p$ Value \\
\hline $\begin{array}{l}\text { Baseline stenosis at side branch } \\
\text { origin }(\%)\end{array}$ & $49 \pm 46$ & $17 \pm 26$ & NS & $14 \pm 15$ & $29 \pm 31$ & NS \\
\hline Stent diameter $(\mathrm{mm})$ & $3.2 \pm 0.3$ & $3.1 \pm 0.3$ & NS & $3 \pm 0.29$ & $3.15 \pm 0.34$ & NS \\
\hline Balloon $\phi /$ Vessel $\phi$ ratio & $1.1 \pm 0.11$ & $1.0 \pm 0.10$ & NS & $1 \pm 0.13$ & $1 \pm 0.1$ & NS \\
\hline Unplanned stent indication & 0 & 11 & NS & 0 & 19 & NS \\
\hline Parent vessel (LAD) & 2 & 16 & NS & 3 & 26 & NS \\
\hline Diabetes & 1 & 4 & NS & 2 & 9 & NS \\
\hline Hyperlipidemia & 2 & 9 & NS & 3 & 13 & NS \\
\hline Native lesion & 3 & 26 & NS & 3 & 29 & NS \\
\hline Chronic total occlusion & 3 & 16 & NS & 2 & 13 & NS \\
\hline Restenosis at stented segment & 2 & 11 & NS & 1 & 13 & NS \\
\hline
\end{tabular}

NS, Not significant; $L A D$, left anterior descending artery.

lesions treated by balloon angioplasty $(5 \%) .{ }^{11}$ Dissection of the dilated artery involving the origin of the branch or intimal disruption blocking the juncture exit have been proposed as mechanisms responsible for occlusion after balloon angioplasty. ${ }^{11,12}$ After stent implantation, other additional factors may be involved, such as the covering of the side branch juncture exit by the stent or permanent displacement of plaque material toward the side branch.

The mechanism of late progression or occlusion at origin of a side branch covered by a stent remains unknown. A totally immersed stent in the arterial wall by itself seems unlikely to produce deleterious effects of the side branch blood flow. Nevertheless, if by chance a metallic portion remains nonendothelialized at the ostial level, thrombus formation may result. In fact, in one of our patients who had a non$\mathrm{Q}$-wave myocardial infarction 1.5 months after the procedure, a late intraluminal filling defect suggestive of thrombus at the origin of a diagonal branch was observed. Moreover, an exaggerated proliferation of smooth-muscle cells on the stent surface reaching the orifice of the side branch could be considered as another pathogenetic mechanism.

Regression or even disappearance at follow-up of a lesion at side branch origin emerges as another interesting phenomenon that may occur in a significant proportion of vessels (26\%). Although there is no definite explanation for these favorable changes, it is possible to speculate on two diverse considerations: (1) ulterior lysis of thrombotic material coming from the stented plaque as a result of the intensive antico- 
agulation regimen or (2) remodeling of plaque architecture at site of side branch origin. To sum up, although our report and a recent study ${ }^{2}$ show favorable evolution of the side branch covered by the stent (low stenosis progression rate and frequent stenosis regression), we recommend that caution be used in deciding to cover a significant side branch given the unpredictability of vessel occlusion.

\section{REFERENCES}

1. Pan M, Medina A, Hernández E, Suárez de Lezo J, Romero M, Melián F, Pavlovic DJ, Cabrera JA, Marrero J, Ortega JR, Segura J. Follow-up patency of side branches covered by an intracoronary Palmaz-Schatz stent [Abstract]. Circulation 1993;88:I-640.

2. Fischman DL, Savage MP, Leon MB, Schatz RA, Ellis S, Cleman MW, Hirshfeld JW, Teirstein P, Bailey S, Walker CM, Goldberg S. Fate of lesion-related side branches after coronary artery stenting. J Am Coll Cardiol 1993;6:1641-6.

3. Pan M, Medina A, Romero M, Suárez de Lezo J, Hernández E, Pavlovic DJ, Melián F, Marrero J, Cabrera JA. Peripheral stent recovery after failed intracoronary delivery. Cathet Cardiovasc Diagn 1992;27:230-3.

4. Medina A, Melian F, Suarez de Lezo J, Pan M, Romero M, Hernández E, Marrero J, Ortega JR, Pavlovic DJ. Effectiveness of coronary stenting for the treatment of chronic total occlusion in angina pectoris. Am J Cardiol 1994;73:1222-4.

5. Schatz RA, Baim DS, Leon M, Ellis SG, Goldberg S, Hirshfeld JW, Cleman MW, Cabin HS, Walker C, Stagg J, Buchbinder M, Teirstein P, Topol EJ, Savage M, Perez JA, Curry RC, Whitworth H, Sousa E, Tio
F, Almagor Y, Ponder R, Penn IM, Leonard B, Levine SL, Fish RD, Palmaz J. Clinical experience with the Palmaz-Schatz coronary stent: initial results of multicenter study. Circulation 1991;83:148-61.

6. Carrozza JP, Kuntz RE, Levine MJ, Pomerantz RM, Fishman RF, Mansour M, Gibson CM, Senerchia CC, Diver DJ, Safian RD, Baim DS. Angiographic and clinical outcome of intracoronary stenting: immediate and long-term results from a large single-center experience. $\mathrm{J}$ Am Coll Cardiol 1992;20:328-37.

7. Herrmann HC, Buchbinder M, Clemen MW, Fischman D, Goldberg S, Leon MB, Schatz RA, Tierstein P, Walker CM, Hirshfeld JW. Emergent use of balloon-expandable coronary artery stenting for failed percutaneous transluminal coronary angioplasty. Circulation 1992; 86:812-9.

8. Colombo A, Maiello L, Almagor Y, Thomas J, Zerboni S, Di Summa M, Finci L. Coronary stenting: single-institution experience with the initial 100 cases using the Palmaz-Schatz stent. Cathet Cardiovasc Diagn 1992;26:171-6.

9. Pomerantz RM, Kuntz RE, Carrozza JP, Fishman RF, Mansour M, Schnitt SJ, Safian RD, Baim DS. Acute and long-term outcome of narrowed saphenous venous grafts treated by endoluminal stenting and directional atherectomy. Am J Cardiol 1992;70:161-7.

10. Medina A, Hernández E, Suárez de Lezo J, Pan M, Melián F, Romero M, Marrero J, Irurita M, Pavlovic DJ. Divided Palmaz-Schatz stent for discrete coronary stenosis. J Invasive Cardiol 1992;4:389-92.

11. Meier B, Gruentzig AR, King SB, Douglas JS, Hollman J, Ischinger T, Aueron F, Galan K. Risk of side branch occlusion during coronary angioplasty. Am I Cardiol 1984;53:10-4.

12. Morimoto S, Hiramitsu S, Yamada K, Uemura A, Kubo N, Mizuno Y. Lesions in side branches of arteries having undergone percutaneous transluminal coronary angioplasty: a histopathologic study. AM HEART J 1990;120:864-72.

\section{AVAILABILITY OF JOURNAL BACK ISSUES}

As a service to our subscribers, copies of back issues of the AMERICAN HEART JOURNAL for the preceding 5 years are maintained and are available for purchase from the publisher, Mosby, at a cost of $\$ 10.00$ per issue. The following quantity discounts are available: $25 \%$ off on quantities of 12 to 23 , and one-third off on quantities of 24 or more. Please write to Mosby-Year Book, Inc., Subscription Services, 11830 Westline Industrial Drive, St. Louis, MO 63146-3318, or call (800)453-4351 or (314)453-4351 for information on availability of particular issues. If unavailable from the publisher, photocopies of complete issues are available from University Microfilms International, 300 N. Zeeb Rd., Ann Arbor, MI 48106, (313)761-4700. 